\section{Ethnicity and Prejudice: A Historical Shift}

Pradeep Acharya

\begin{abstract}
The paper principally aimed to present a brief overview of the historical shift on the notion of ethnicity and prejudice around the wider global context with particular focus on local Nepalese context has solely based on the secondary information obtained from the review of pertinent literatures on ethnicity. The genesis of the approaches to ethnicity comprises some conceptual idea on ethnicity regarding its emergence and usage as a term in the social sciences. Ethnicity can be said to be very closely interlinked with prejudice in policy and practice at the level of individual, society and the state. The historical evidence suggests that there has been a gradual shift on the notion of both ethnicity and prejudice around different places at different time periods. In addition, it does contain significant research problems, which, can surely be elaborated, and its full significance drawn.
\end{abstract}

Keywords: Ethnicity, prejudice, boundaries, social constructionist model, multilevel theory

\section{Introduction}

Recent newspaper headlines and various forms of public debates on political, social and cultural realms may well characterize the present concern on the concept and practice of ethnicity in the country. On the one hand, the rapid urbanization and the growth of multicultural cities have made the issue of ethnicity more relevant in everyday discussion in a seemingly diverse ways and that the most societies around the world are said to be heterogeneous in composition implying the various mode of categorization of human. On the other hand, the socially constructed notion of ethnicity has very different meanings for state, society and individual and that the ethnicity at work is no longer same as it was before. Ethnicity and prejudice, both being multi-vocal terms, requires "rethinking (Jenkins, 2008)" in this context. Ethnicity should be studied in the "historical context (Gellner, 2001; Guneratne, 2002)". It is important not only because it is one of the interesting core areas of anthropology for examining human similarities and differences from physical and cultural point of view but also to address the present debates and issues on ethnicity.

The fundamental goal of this paper is to present a brief overview of the historical shift on the notion and paradigms of the concept of ethnicity and prejudice in theoretical orientations and practices in around the world and in particular context of Nepal. The contents of this paper are solely based on the secondary information obtained from the review of pertinent literatures on ethnicity. A section on the genesis of the approaches to ethnicity quotes some conceptual idea on ethnicity, as how ethnicity as a term emerged and used in social sciences. Then the historical shift in theoretical orientation to prejudice and the dominant social policy of the time has been briefly discussed. The strength of the paper, for me, is that it does contain significant research problem, which, I feel, can surely be elaborated, and its full significance drawn.

\section{Changing Notion of Ethnicity \\ 2.1. The Global Trend}

As a term, 'ethnicity' is recognized by sociologists as having relatively recent coinage. Eriksen (1993) cites Glazer and Moynihan as noting that the word's first appearance was in the Oxford English Dictionary of 1972. As Regmi (2003) quotes Glazer and Moynihan (1975), the term 'ethnicity' was for the first time used around 1953. The word 'ethnic' is derived from the Greek 'ethnos' (in turn derived from 'ethnikos'), originally meaning 'heathen' or 'pagan' i.e. an offensive term that deliberately insults somebody who does not acknowledge the belief of Christianity or in other words, the term 'ethnicity' was originally used to substantiate the difference among the Christians and non-Christians. It was used in this sense from the mid fourteenth century until the mid nineteenth century, and then it gradually began to develop 'racial' connotations (to be linked with lineage and kin solidarity). 'Ethnicity' and 'race' are not popularly regarded as mutually exclusive concepts as 'ethnicity' is deemed to 
be more polite and less controversial term for 'race' (Popeau, 1998). Since then, the notion of 'ethnicity' has been changing in terms of its meaning and usages but one thing common is that it has always been based on the dialectic interplay (Jenkins, 2008) of both perceived similarities and differences in terms of some markers.

Anthropological literatures from 1950 to 1994 reveal a change in the language of the subject. Words such as 'function' and 'social structure' have become less common. Those like 'class', 'infrastructure' and 'contradiction' had a brief spell of popularity in the 1970s, while terms such as 'discourse', and 'resistance and 'symbolic capital' have steadily grown more popular since the early 1980s. Such terminological changes reflect shifts in the dominant perspectives of the subject (Eriksen, 1995). Moreover, the change is obvious as nothing is constant except constant change.

Until the 1960s, and in many cases later, social anthropologists studying ethnicity and inter-group relations typically concentrated upon ethnicity as a corporate social phenomenon. They oriented themselves to the identification and understanding of substantial ethnic groups, conceptualized as distinct-from-each-other, culturebearing collectivities. This approach still tacitly characterizes the working practices of many anthropologists. As ontology of the human world it emerged from the social anthropological preoccupation - itself a legacy of the long-standing and disproportionate theoretical sway exercised by structural functionalism during the discipline's formative years - with social structure, social groups and their systematic interrelationships, and social order and integration. During the colonial and immediately post-colonial periods, social anthropology's theoretical preoccupation with corporate groups and integrated social systems was manifest in an orthodox assumption that the subject matter of the discipline - 'primitive' people -was most commonly organized into tribal groups. By the 1960s the notion of the tribe was beginning to be replaced by the, perhaps less embarrassingly colonial, 'ethnic group'. The event that most clearly marked an anthropological paradigm shift, from the study of 'tribal society' to the social constructionist model of 'ethnic groups' which is current

\section{$88 \mid$ Pradeep Acharya}

today, was the publication of Ethnic Groups and Boundaries by Barth (1969). Barth identified four theoretical features of the conventional, taken-for-granted model of the corporate, culturally distinct ethnic group; first, such a group was biologically selfperpetuating; second, members of the group shared basic cultural values, manifest in overt cultural forms; third, the group was a bounded social field of communication and interaction; and fourth, its members identified themselves, as were identified by others, as belonging to that group (Jenkins, 2008). He has summarized the 'Basic Social Anthropological Model of Ethnicity' in terms of four major propositions: - i) Ethnic identification always involves a dialectical interplay between similarity and difference; ii) Ethnicity is centrally a matter of shared meanings i.e. the culture and that the culture is also produced and reproduced during interaction; iii) Ethnicity is no more fixed or unchanging than the way of life of which it is an aspect or the situations in which it is produced and reproduced; iv) Ethnicity, as an identification, is collective and individual, externalized in social interaction and the categorization of others, and internalized in personal self-identification.

Barth broke away from the Herderian canon in anthropology, according to which each ethnic group represented a historically grown, uniquely shaped flower in the garden of human cultures. Instead of studying each of these cultures in separate ethnography, Barth and his collaborators observed how the boundaries between two ethnic groups are maintained, even though their cultures might switch from one side of the boundary to the other. Barth's approach to ethnicity thus no longer resembled an exercise in Linnean taxonomy but in social ecology. Barth's 'constructivism' claim that ethnicity is the product of a social process rather than a cultural given, made and remade rather than taken for granted, chosen depending on circumstances rather than ascribed through birth. In the following two decades, prolonged battles emerged between devotees of this constructivist perspective and adherents to older views that were more in line with Herderian notions of the binding power of ethnicity and culture, which has often been framed in dichotomous terms; "primordialism" - which underlined that ethnic membership was acquired through birth and thus represented a 'given' characteristics of the social world, was pitted against "instrumentalism" - which maintained that individuals 
choose between various identities according to self-interest. "Essentialism" - emphasizing the privileging the trans-contextual stability provided by ethnic cultures was opposed to "situationalism" - emphasizing how individuals identify with different ethnic categories depending on the logic of the situation. "Modernist" attributed the salience of ethnicity to the rise of modern nation-state, while "perennialists" insisted that ethnicity represented one of the most stable principles of social organization in human history. These binary oppositions appeared in various constellations and combinations i. e. "construtivist-instrumentalistcircumstantialist-interest” versus “essentialist- primordialistperennialist-identity", the former asserting that the ethnic distinctions were primarily driven by the changing interests of individual or collective actors and the latter insisted on the subjectively felt reality and deeply rooted character of ethnic identity (Wimmer, 2008). By acknowledging the diversion of our efforts away from understanding why ethnicity appears in such variable forms due to be occupied into such dichotomous definitional debates, Wimmer has proposed a Multilevel Process Theory of the Making and Unmaking of Ethnic Boundaries, which explains ethnic boundaries as the result of negotiations between actors whose strategies are shaped by the characteristics of the social field. The social field is characterized by the prevailing 'institutional order', 'distribution of power' and 'political networks' which determine which actors will adopt which strategy of ethnic boundary; strategies could be many like, 'Expansion of Boundaries', 'Contraction of Boundaries', 'Inversion of the Hierarchy', 'Repositioning oneself in the Hierarchy', and 'Blurring Boundaries by undermining the Categorization' etc.

\subsection{The Nepalese Context}

Before we discuss the historical shift in ethnicity and prejudice in Nepal, it is relevant to look back into the history of anthropological researches in Nepal. After 1950s, Nepal followed an open door policy and as a result Nepal became a fertile field for sociological and anthropological studies. Comprised of a multitude of linguistic, cultural and ethnic groups living in a relatively small area of land, Nepal has attracted unprecedented numbers of scholars and students of Western countries and Japan, during the past four decades. Fisher (1985) in a precise summary of the works of foreign scholars writes that one of the remarkable features of anthropology in Nepal is that those foreign scholars who have conducted research studies in Nepal have tended to follow their own national trends; British anthropologists like Caplan and Caplan (1970, 1972) have evinced strong interests in traditional concerns of social anthropology such as Land Tenure, Social Structure and Politics; Americans have pursued various theoretical interest ranging from the Symbolic (Ortner, 1976) and Psychological (Paul, 1962) to Ecological and Economic (Fisher, 1985); Germans have shown strong interest in Culture History (Oppitz, 1968) and Material Culture (Schmidt, 1975); and French have tended towards detailed Ethnographic accounts (Pignede, 1970). The contributions made by Nepali Sociologists and Anthropologists are no less important than those of foreigners. Bista, (1967) provides general ethnographic descriptions delineating cultural groups among the Nepali people. It serves as a basic guideline to those researchers who are particularly interested in studying Nepali peoples and their histories and cultures. Additional studies and research are those of G.S. Nepali, B.K. Shrestha, Khem B. Bista, B.P. Upreti, T. S. Thapa, Shyam Pd. Adhikari, D. R. Dahal, Navin Rai, C. Mishra, R.K. Regmi and D. P. Rajauriya etc. There are also several scholars and researchers, although not trained in sociology and anthropology, such as Tulsi Diwas, P. R. Sharma, Soyambhu Lal Joshi and Satyamohan Joshi whose works are nevertheless of anthropological value (Gurung, 1990). Macdonald (1974), regarding the foreign scholarship in Nepal, pointed that those foreign scholars came to Nepal from different national backgrounds and academic systems, to respond to questions which were considered urgent in their own national academic contexts and the serious Western students who collected materials from widely dispersed areas of Nepal took back to Europe, Japan and USA in direct response to bread-and-butter and career imperatives, and published in languages which are sometimes not widely read in Nepal. However, all this activity is often not nearly as chaotically bourgeois as it appears to Nepalese eyes.

The history of anthropological practices in Nepal, discussed above, clearly show that the development of studies on ethnicity started 
from the ethnographic descriptions of various ethnic groups as a distinct collectivities. Their culture, rituals, religions were focused as well as their adaptation to the ecology and their practice of natural resource management to a great extent, while, the issue of ethnic identity, social boundaries have just come up very recently. For Levine (1987), Humla experience suggested the incidence of semi-permeable boundaries, particularly influenced by alliance and economic exchanges. Some focused on Ethnicization of politics (Pfaff-Czarnecka et. all, 1999) and some (Hangen, 2005) noticed the political mobilization of racial identities particularly by the subaltern people. Hachhethu (2003, and Sharma, 1997), see that the ethnic politics of Nepal in the 1990s seems to have elements conforming with both the primordialist and instrumentalist models. Pfaff-Czarnecka (1999) takes ethnic activism in Nepal as having elements of instrumentalism greater and lesser primordialism i.e. elitist nature. Gurung (1999) states that, ethnic movements is headed to make hitherto deprived ethnic groups equal partners in the development of a single territorial Nepalese nation-state because the movement is the outcome of age old suppression through imposition of stratified hierarchical model by the Hindu rulers of Nepal. The widely accepted and adopted approach to the study of ethnicity in Nepal is addressing the issue of 'dominant group (Hill-Bahun Chhetris) and minority group’. In contrary, Dahal (1995) stresses on the notion of dominant 'individuals' not the dominant 'caste'. For some ethnicity is 'fluid' (Fisher, 2001), 'fluidity' (Gubhaju, 1991) in terms of boundaries which tend to be heightened in terms of some cultural markers in one situation while the other markers in some other situations. Some scholars' argument is in contrary to the assumptions of many scholars who predicated a common ethnic identity in terms of a shared culture. For Guneratne (2002), ethnic identity is not measured by checking off items in a list, rather it is relational and processual, and like any ethnic phenomenon it must be understood in its historical context.

\section{Perspectives on Prejudice: Nepal and Abroad}

Duckitt (2002) describes a historical shift on the theoretical orientations to prejudice in the world context, into six major epochs. The first epoch, upto 1920s, during which, the main issue was white domination and colonial rule of 'backward people'.

\section{2| Pradeep Acharya}

Prejudice, then, was defined as a natural and positive thing. Hence, Domination, Discrimination and Segregation were dominant social policy of that time. The second epoch during 1920s-30s, was characterized by the challenge raised against the legitimacy of white domination and pervasive prejudice. Prejudice, then, was defined as an unconscious defense through which social stress and frustration were displaced through the scapegoating of out groups and minorities. To some extent it was realized that prejudice are irrational and unjustified reaction to people who are different. During the third epoch 1940s-50s, the major issue was Nazi racial ideology and the holocaust (i.e. mass destruction). Prejudice was seen as intimately associated with political intolerance which was said to be related to fascist and right wing ideology and values, and that they were viewed as expressions of pathological needs within authoritarian personalities. Liberal democracy, political tolerance was the dominant social policy of the time assuming that the democratic social structures and values will erode intolerance and prejudice. Fourth epoch during the 1960s, the issue was a sort of institutionalized racism in the American south, and prejudice, then, was defined to be rooted in social structure. Hence, the desegregation, integration were major social policy, assuming that anti-discriminatory laws will lead to inter-group contact which will erode prejudice. At the fifth, 1970s, problem of informal racism and discrimination in the North America aroused and prejudice was defined as expression of the interest of dominant white group i.e. power relations. Affirmative action, minority empowerment were major social policy with a major aim for reducing intergroup inequality. Finally, the sixth epoch from 1980s to 1990s involved the stubborn persistence of stereotyping, prejudice and discrimination as the major issues. Definition of prejudice was said to be based on categorization and it was believed that universal human process might underlie prejudice and discrimination/intergroup favoritism results by simply classifying individuals into completely arbitrary minimal groups. Multiculturalism: multicultural policies to provide minorities with esteem and foster positive non-threatened identities and tolerance for all groups was the priority of social policy and probably it is widely accepted current policy among different societies nowadays.

Even though the one single piece of literature on the history of prejudice particularly in the context of USA, reviewed in the 
preceding paragraph, does not reflect the scenario of the whole world, it clearly puts forward that the prejudice which used to be taken as a normal phenomenon has been now realized as a thing of just contrary to that of the past. This change in theory and practice of prejudice has taken place not only in the western world but in country like Nepal in the course of time. If we put side by side the Nepalese context to the Duckitt's idea, the epochs in terms of time period goes this way: 1) up to the 1920 A.D. equivalent to 1977 B.S.; 2) 1920 s to 1930 s i.e. 1987 B.S.; 3) 1940 s to $1950 \mathrm{~s}$ equivalent to 2007 B.S.; 4) 1960s; 5) 1970s; 6) 1980 to 1990 equivalent to 2046 B.S. Nepal was ruled by Ranas during the first two epochs parallel to Duckitt's idea in terms of time line. The hierarchical classification of society based on caste by formalizing the Civil Code was remarkable feature of the period in Nepal which manifested the inter-caste-ethnic relation and prejudice of the time. Third epoch featured the overthrow of Rana rule and restoration of full fledges monarchy and multiparty democracy was the major political events of the country. Initiation of party less Panchayat system was a major milestone during the 1960s in Nepal. Finally, restoration of multiparty democracy characterized the final decade of the then millennium. In this context, the models of ethnicity as outlined by Pradhan (2002), somehow indicates the changing perspectives on ethnicity at the level of state which is relevant to the then nature of prejudice. In Nepalese society the historic view is as follows, divided into mainly three epochs: 1 ) 2007B.S./ 1950A.D. to 2017B.S./1960A.D.; 2) 1960 A.D. to 1990 A.D.; 3) 1990 onwards. The first epoch involves the Gorkhali and Rana regimes for the most part and the immediate period of the advent of democracy in Nepal. During that period 'plural and hierarchical' thesis was dominant in Nepalese society. Cultural pluralism was recognized but differences were translated into hierarchy with reference to caste system and Parbatiaya values. The second epoch involves the Panchayat period, with a 'homogeneous and non-hierarchical' perspectives which was the anti-thesis of the former one. Cultural difference was not recognized and assimilation into homogeneous national culture was envisioned. Ethnicity was not the basis for Legal identity. Thirdly, the period after the restoration of democracy is somehow a synthesis of both of the previous ideas i.e. a plural and nonhierarchical nation as stated in the then constitution. Ethnicity became one of the bases of legal identity (Pradhan, 2002). It must be mentioned that the 'three epochs' just presented here, are principally about caste and ethnicity proper as such not to prejudice but it could be surely useful to draw conclusion on prejudice from such characterization of the three epochs.

Now the socio-political scenario has changed drastically since the 1990s. After a decade long violent insurgency Nepal is now a republic and new constitution writing process is undergoing. In the context of the major focal concepts of this study prejudice and ethnicity, the issue of prejudice done at state level has now highly raised. Thus if the already mentioned three epochs affirmed by Pradhan are supposed to be the historic view, then situation prevailing nowadays could obviously be the fourth one. Here, what we can conclude that, like the trend of the world Nepal too changed her pattern of ethnicity and practices of prejudice with time. Domination and discrimination gradually changed to tolerance and affirmation; rigidity of boundaries became fluid in some instances despite of being "much stiffer (Mishra, 2010)" on some others.

There was no national ethnic policy in Nepal in the past nor is there any at the present but the major issues can be whether Nepal is a 'garden of all castes and ethnic groups' in a real sense and whether the monopoly of the few dominant caste groups end. In this context, social policy should be to accomplish social integration which is a condition of achieving a relatively cohesive and functioning interaction system in a society among different people as a precondition to national integration. National integration is a progressive process of identifying commonalities with respect to common goods but maintaining and promoting the distinct ethnic identity of each group through social integration within the framework of the current international political boundaries. To achieve national integration, all the ethnic groups must have shared values in which the cultural aspirations of each groups are also reflected (Bhattachan and Pyakuryal, 1996). Here, it is noteworthy to quote Professor C. Mishra (2010), who straightforwardly asserts: 
“The argument that, 'there was no national ethnic policy in Nepal in the past nor is there any at the present' is false or invalid. There might have been no national policy that one might have liked or there might have been no government document titled 'National Ethnic Policy of Nepal' or some such. But there were caste and ethnic policies all around. If caste and ethnicity were salient organizing devices economically, politically and culturally, the argument that there was no ethnic policy would not stand to reason"

\section{Concluding Remarks}

There had been a dramatic shift in the orientation toward ethnicity in terms of approaches used in the related studies. Though, studies on prejudice are very few done in the context of Nepal, the history is evident of its metamorphosis in terms of approach and actual practices. Both conscious and obvious factors are responsible in such a transformation on the pattern of ethnicity and prejudice in Nepal in her history. Most of the studies in ethnicity in Nepal are not equipped with appropriate theories and models and the academic sophistication too is too low here as compared to west which is, among other things, due to the relatively new introduction of sociological and anthropological researches in Nepal. Despite of the substantive contribution in anthropology of Nepal from both domestic and foreign scholars, studies on ethnicity, boundaries is less common and when it comes to prejudice in everyday life it is much less. Locating the existing cultural and ethnic groups is still under process. Ethnicity, in any society of the world is basically a process of categorization of people into different types in terms of various markers. This process of categorization and the consequent categories out there create social boundaries among people which are manifested in particular behavioral patterns in everyday life. The history of studies of ethnicity in Nepal seems to be more focused on ethnicity in static sense i.e. ethnographic details of human collectivities as relatively unchanging closed entity. Therefore, it is necessary to see them in terms of ethnicity as process i.e. making of boundaries, fluidity of boundaries as well as the stiffening of boundaries, variations in categorization and identification among groups in different times and places.

\section{6 | Pradeep Acharya}

Within the framework of the discussion made above, future outlook could be to explore how the people categorize themselves and others as a particular ethnic category in terms of the markers they feel relevant among some ethnic groups in Nepal in order to understand the ways social boundaries are created and maintained in everyday life of people in terms of attitudinal and behavioral aspects of prejudice as a result of ethnicity as a process of social categorization i.e. folk categorization and everyday life in historical context.

\section{References}

Bhattachan, K.B., Pyakuryal, K.N. (1996). The Issue of National Integration in Nepal, An Ethnoregional Approach. Occasional Paper in Sociology and Anthropology, Vol.5, pp.17-38, Kathmandu: Central Department of Sociology and Anthropology, Tribhuvan University, Nepal.

Duckitt, J. (2002). Reducing Prejudice; a Historical and Multilevel approach. Understanding Prejudice, Racism and Social Conflict, Augoustinos, M. and Reynolds, K. edited. pp 253-272. Britain: Sage Publication.

Eriksen, T.H. (1995). Small Places Large Issues: An Introduction to Social and Cultural Anthropology. USA: Pluto Press.

Fisher, W. F. (2001). Fluid Boundaries, Forming and Transforming Identity in Nepal. USA: Columbia University Press.

Gellner, D. (2001). How should one Study Ethnicity and Nationalism. Contribution to Nepalese Studies, Vol.28, No.1, January, CNAS, TU.

Gubhaju, B. (1991). The Fluidity of Ethnicity, the case of Nepali and Newar Identity in US. Contribution to Nepalese Studies.Vol.26, No.1, January 1999, CNAS/TU, Nepal

Guneratne, A. (2002). Many Tongues, One People: The Making of Tharu Identity in Nepal. USA: Cornell University Press.

Gurung, O. (1990). Sociology and Anthropology, an 
Emerging Field of Study in Nepal. Occasional Papers in Sociology and Anthropology, Vol.2, Central Department of Sociology and Anthropology, Tribhuvan University, Nepal

Hachhethu, K. (2003). Democracy and Nationalism Interface

Between State and Ethnicity in Nepal. Contributions to Nepalese Studies, Vol.30, No.2, Centre for Nepalese Studies, Tribhuvan University, Nepal

Hangen, S. (2005). Race and Politics of Identity in Nepal.

Ethnology, Vol.44, University of Pittsburg, URL: http:www.jstor.org/stable/3773959, pp.49-64

Jenkins, R. (2008). Rethinking Ethnicity, Arguments and Exploration. Great Britain: Sage Publication.

Levine, N.E. (1987). Caste, State and Ethnic Boundaries in Nepal. The Journal of Asian Studies, Vol.46, No.1 (Feb.,1987), Association for Asian Studies.

Macdonald. A.W. (1974). Emergence and Development of Sociological and Anthropological Research in Nepal. Social Sciences in Nepal, Institute of Humanities and Social Sciences. Tribhuvan University, Nepal.

Mishra, C. (2010). Comments by Chaitanya Mishra on seminar paper on 'Ethnicity and Prejudice: A

Historical Shift' by Ph.D. candidate Pradeep Acharya, August 11, 2010 at the Central Department of Sociology and Anthropology, Tribhuvan University, Nepal.

Pfarr-Czarnecka, J., Senanayake, D.R., Nandy, A. and Gomez, E.T.

(1999). The State and Identity Politics in Asia. New Delhi: Sage Publications.

Popeau, J. (1998). Race/Ethnicity. Core Sociological Dichotomies. Jenks, C. edited. Great Britain: Sage Publication.

Pradhan, R. (2002). Ethnicity, Caste and a Pluralist Society. State of Nepal. Dixit/Ramchandran edited. Kathmandu: Himal Books, Nepal.

Regmi, R. (2003). Ethnicity and Identity, Occasional Paper in Sociology and Anthropology, Vol.8, pp.1-11, Kathmandu: Central Department of Sociology and Anthropology, Tribhuvan University

Wimmer, A. (2008). The Making and Unmaking of Ethnic
Boundaries: A Multilevel Process Theory. American Journal of Sociology, Vol.113, No.4, January 2008. pp.970-1022 